University of Nebraska - Lincoln

DigitalCommons@University of Nebraska - Lincoln

U.S. Environmental Protection Agency Papers

U.S. Environmental Protection Agency

2004

Heterotrophic plate count bacteria-what is their significance in drinking water?

\author{
Martin J. Allen \\ Awwa Research Foundation \\ Stephen C. Edberg \\ Yale University \\ Donald J. Reasoner \\ U.S. Environmental Protection Agency
}

Follow this and additional works at: https://digitalcommons.unl.edu/usepapapers

Part of the Civil and Environmental Engineering Commons

Allen, Martin J.; Edberg, Stephen C.; and Reasoner, Donald J., "Heterotrophic plate count bacteria-what is their significance in drinking water?" (2004). U.S. Environmental Protection Agency Papers. 93.

https://digitalcommons.unl.edu/usepapapers/93

This Article is brought to you for free and open access by the U.S. Environmental Protection Agency at DigitalCommons@University of Nebraska - Lincoln. It has been accepted for inclusion in U.S. Environmental Protection Agency Papers by an authorized administrator of DigitalCommons@University of Nebraska - Lincoln. 


\title{
Heterotrophic plate count bacteria-what is their significance in drinking water? ${ }^{\text {is }}$
}

\author{
Martin J. Allen ${ }^{\mathrm{a}, *}$, Stephen C. Edberg ${ }^{\mathrm{b}}$, Donald J. Reasoner ${ }^{\mathrm{c}}$ \\ ${ }^{a}$ Awwa Research Foundation, 6666 W. Quincy Avenue, Denver, CO 80235, USA \\ ${ }^{\mathrm{b}}$ Yale University School of Medicine, New Haven, CT, USA \\ ${ }^{\mathrm{c}}$ U.S. Environmental Protection Agency, Cincinnati, OH, USA
}

Presented at the NSF International/World Health Organization symposium on HPC Bacteria in Drinking Water, April 22-24, 2002, Geneva, Switzerland.

\begin{abstract}
While the literature documents the universal occurrence of heterotrophic plate count (HPC) bacteria in soils, foods, air, and all sources of water, there is a lingering question as to whether this group of organisms may signal an increased health risk when elevated populations are present in drinking water. This paper reviews the relevant literature on HPC bacteria in drinking water, the lack of clinical evidence that elevated populations or specific genera within the HPC flora pose an increased health risk to any segment of the population, and the appropriate uses of HPC data as a tool to monitor drinking water quality changes following treatment. It finds no evidence to support health-based regulations of HPC concentrations.

(C) 2003 Elsevier B.V. All rights reserved.
\end{abstract}

Keywords: HPC; Drinking water; Heterotrophic bacteria

\section{Introduction}

\subsection{Terminology}

The term "heterotrophic bacteria" includes all bacteria that use organic nutrients for growth. These bacteria are universally present in all types of water, food, soil, vegetation, and air. Under this broad definition, primary and secondary bacterial pathogens are included, as are coliforms (Escherichia, Klebsiella, Enterobacter, Citrobacter, Serratia).

\footnotetext{
t The views expressed are those of the authors and do not necessarily reflect those of the Awwa Research Foundation or the U.S. Environmental Protection Agency.

* Corresponding author.
}

Heterotrophic plate count (HPC) bacteria represent those microbes isolated by a particular method, whose variables include media composition, time of incubation, temperature of incubation, and means of medium inoculation.

Other terms that have been used to describe this group of bacteria in water include "standard plate count", "total viable count", "total count", "plate count", "total bacterial count", "water plate count", "colony count", "aerobic mesophilic viable count", and "autochthonous flora". All of these terms describe the same general bacterial group, i.e., the population of bacterial colonies produced on an agar-based medium under defined incubation temperature and time. With the 16th edition of Standard Methods for the Examination of Water and Wastewater, "Heterotrophic Plate 
Count" was the term selected to designate this group of bacteria in water.

It is important to understand that while the term "heterotrophic bacteria" denotes all bacteria requiring organic nutrients for growth, all HPC methods enumerate only a fraction or subpopulation of heterotrophic bacteria in any water, food, soil, vegetation, air, etc. Further, it is not possible to know which percentage of the subpopulation of heterotrophic bacteria is enumerated by any HPC method, and it is not possible to differentiate which of the subpopulation includes potential pathogens.

\subsection{HPC media and methods}

Through the years, many "standard methods" have been used to enumerate the very broad range of genera that comprise HPC populations in drinking water. Examples of such methods and their respective developmental histories are described in "Monitoring Heterotrophic Bacteria in Potable Water" (Reasoner, 1990).

Based on decades of research with a variety of HPC media and methods, the following observations have been made:

1. Although often referred to as non-selective media, all media used for HPC determinations, along with respective time and temperature conditions, are "selective" for those bacteria that can grow under those specific conditions.

2. There is no single medium or method that will recover or enumerate all bacteria in the water being analyzed.

3. Many heterotrophic bacteria that are present in water are not culturable at present.

4. The choice of culture medium, temperature, and incubation time are important with regard to HPC results from a given water sample.

- Both high-nutrient and low-nutrient media are used for HPC determinations.

- High-nutrient media are better for enumeration of bacteria from animals and humans.

- Low-nutrient media are better for enumeration of water-based bacteria (autochthonous) found in aquatic systems, including drinking water. The most commonly employed heterotrophic medium is R2A. It was designed specifically as a low-nutrient, low-ionic strength formulation to isolate bacteria that have a water-based, rather than mammalian lifestyle (Reasoner, 1990).

- New methods that employ fluorescent substrates have been developed (Jackson et al., 2000). Fluorescence permits more rapid results and has the potential for automation.

5. Time and temperature of incubation are very significant variables. Table 1 presents examples of variable differences on the resulting $\mathrm{cfu} / \mathrm{ml}$ (Reasoner, 1990).

- High-temperature incubation $\left(35-37{ }^{\circ} \mathrm{C}\right)$ and short incubation time $(34-48 \mathrm{~h})$ favor the growth of bacteria from animals and humans.

- Low-temperature incubation $\left(20-28{ }^{\circ} \mathrm{C}\right)$ and longer incubation time (5-7 days) favor the growth of water-based bacteria.

6. All bacterial pathogens and opportunistic pathogens are heterotrophic bacteria, some of which can grow on media used for determining standard plate counts or heteroptrohic plate counts in drinking water. However, it is necessary to use selective or

Table 1

Comparison of HPC results using different media (adapted from Reasoner, 1990)

\begin{tabular}{|c|c|c|c|}
\hline \multirow{2}{*}{$\begin{array}{l}\text { Temperature } \\
\left({ }^{\circ} \mathrm{C}\right)\end{array}$} & \multicolumn{3}{|c|}{ Method (cfu/ml) } \\
\hline & PP & SP & MF \\
\hline 35 & 3137 (SPC) & - & 4273 (m-HPC) \\
\hline 20 & 170 (SPC) & 440 (R2A) & 510 (m-HPC) \\
\hline \multirow[t]{2}{*}{20} & - & 4000 (R2A) & 12 (m-HPC) \\
\hline & - & $1000(\mathrm{R} 2 \mathrm{~A})$ & $110(\mathrm{~m}-\mathrm{HPC})$ \\
\hline \multirow[t]{2}{*}{35} & - & 20 (R2A) & 6 (m-HPC) \\
\hline & - & 4 (R2A) & $<1(\mathrm{~m}-\mathrm{HPC})$ \\
\hline 35 & 277 (SPC) & - & 283 (m-HPC) \\
\hline \multirow[t]{2}{*}{20} & 1123 (NA) & - & 1217 (m-HPC) \\
\hline & 1192 (NA) & - & 1192 (R2A) \\
\hline 35 & 22 (SPC) & 200 (R2A) & 32 (m-HPC) \\
\hline 28 & 80 (SPC) & 360 (R2A) & 140 (m-HPC) \\
\hline 20 & 22 (SPC) & $90(\mathrm{R} 2 \mathrm{~A})$ & 47 (m-HPC) \\
\hline \multirow[t]{2}{*}{35} & 53 (SPC) & - & 66.7 (m-HPC) \\
\hline & 53 (SPC) & - & $57.1(\mathrm{R} 2 \mathrm{~A})$ \\
\hline 26 & 590 (SPC) & 1550 (R2A) & - \\
\hline \multirow[t]{3}{*}{22} & 100 (YEA) & 710 (YEA) & - \\
\hline & 440 (R2A) & & - \\
\hline & 100 (YEA) & 3900 (R2A) & - \\
\hline
\end{tabular}

cfu, colony-forming units.

Media: $\mathrm{SPC}=$ standard plate count agar; $\mathrm{NA}=$ nutrient agar; YEA= yeast extract agar; R2A medium; m-HPC medium; m-HPC was published originally as $\mathrm{m}$-SPC medium. 
differential media to distinguish pathogens and opportunistic pathogens from non-pathogens.

7. There are differences between pour-plate, spreadplate, and membrane filtration methods.

- The pour plate method generally yields lower bacterial counts regardless of medium or time of incubation and is generally limited to 0.1 to 1.0 $\mathrm{ml}$ sample volume.

- The spread plate method generally yields higher counts than other methods but is limited to a 0.1 to $1.0 \mathrm{ml}$ sample volume.

- The membrane filtration method is more flexible because it allows for the analysis of sample volumes greater than $1.0 \mathrm{ml}$.

- Different methods and media will produce markedly different HPC concentrations (see Table 1).

\section{Heterotrophic bacteria genera}

As described above, the genera enumerated by any HPC method are highly variable since the cultivation medium of choice, incubation temperature, incubation time, origin (river, surface water reservoir, treated and disinfected drinking water, etc.), season of the year, and age of the water sample have a significant effect on which genera will grow under these selected conditions. This same variability applies to the analysis of food, dairy, and other environmental determinations.

As mentioned above, the bacteria that fit the scientific definition of heterotrophic bacteria (use of organic nutrients as the energy source) include $\mathrm{Myco}$ bacterium avian complex and Legionella and may not grow on HPC media. Accordingly, if one wishes to determine if these genera are present in drinking water, specific methods tailored to their specific growth requirements must be employed.

\subsection{HPC genera found in drinking water}

There is a significant body of information in the literature on genera that comprise HPC populations enumerated in drinking water using different methods. Table 2 includes genera often reported in the literature (LeChavallier et al., 1980; Herson and Victoreen, 1980; Briganti and Wacker, 1995).
Table 2

HPC genera commonly found in drinking water

\begin{tabular}{|c|c|}
\hline Acinetobacter & Methylomonas \\
\hline Actinomycetes $^{\mathrm{a}}$ & Micrococcus \\
\hline Alcaligenes & Mycobacterium $^{\mathrm{a}}$ \\
\hline Aeromonas $^{\mathrm{a}}$ & Morexella \\
\hline Aeromonas hydrophila $^{\mathrm{a}}$ & Nitrobacter \\
\hline Arthrobacter & Nitrosomonas \\
\hline Bacillus & Nocardia $^{\mathrm{a}}$ \\
\hline Beggiatoa & Proteus \\
\hline Citrobacter freundi & Pseudomonas \\
\hline Corynebacterium & P. cepacia \\
\hline Crenothrix & P. fluorescens \\
\hline Desulfovibrio & P. maltophilia \\
\hline Enterobacter agglomerans & Serratia liquefaciens \\
\hline Enterobacter cloacae & Sphaerotilus \\
\hline Escherichia coli & Sphingomonas \\
\hline Flavobacterium & Staphylococcus \\
\hline Flavobacterium meningosepticum & Streptococcus \\
\hline Gallionella & Streptomyces \\
\hline Hafnia alvei & Yersinia enterocolitica \\
\hline Klebsiella pneumoniae & \\
\hline
\end{tabular}

In addition to the above genera, HPC populations from drinking water include many pigmented (orange, yellow, pink) organisms that are difficult to speciate.

${ }^{\text {a }}$ Generally not recovered by HPC methods as referenced in Standard Methods for the Examination of Water and Wastewater, 20th edition.

\subsection{HPC genera found in food}

All of the HPC genera found in drinking water are also common in foods, and humans ingest large numbers of these microorganisms daily. While the upper range of HPC populations in drinking water average 5000-10,000 cfu/ml (Reasoner, 1990), HPC populations in food are consistently log concentrations higher (Wadhwa et al., in press). This difference is because food provides distinctly different physical and physiological conditions than drinking water. With higher concentrations of carbohydrates, protein, and ionic strength, food is much closer to the human physiological state than drinking water, which is essentially devoid of nutrients and ionic strength. Accordingly, microbes that can multiply in humans and cause disease can grow in foods but do not multiply in drinking water. Virtually all foods contain many thousands times more bacteria than drinking water. Table 3 provides examples of microbial genera and densities found in foods.

Wadhwa et al. (in press) concluded, based on both observed microbial content and the potential presence 
Table 3

Examples of microbial indicators and densities found in food (Wadhwa, 2002)

\begin{tabular}{lll}
\hline Indicator/genus & Food & Density $(\mathrm{cfu} / \mathrm{g})$ \\
\hline Aerobic plate count & ground beef & $8 \times 10^{3}$ \\
Aerobic mesophilic & retail white cabbage & $10^{6}$ \\
bacteria & retail lettuce & $10^{6}$ \\
& retail cucumber & $10^{5}$ \\
Aeromonas spp. & retail green pepper & $10^{4}$ \\
& green leaf lettuce & $7.3 \times 10^{3}$ \\
Aerobic plate count & spinach & $5.1 \times 10^{3}$ \\
\hline
\end{tabular}

of large numbers of pathogens or their indicators in food, that food is more of a health risk than drinking water. They also stated that naturally occurring bacteria (HPC or autochthonous flora) do not have virulence factors, making their numbers in drinking water irrelevant to health risk except in the most severely immunocompromised subpopulations, who are fully aware of their medical condition and need to exercise appropriate dietary and other preventive measures. (Edberg, 1997).

\section{Association of health risk and HPC bacteria}

As noted earlier, the broad definition of HPC bacteria includes a wide range of bacterial genera, which may include primary and secondary pathogens. Specific HPC genera that some consider as opportunistic pathogens enumerated by HPC methods include Aeromonas, Klebsiella, and Pseudomonas. Because of this fact, regulatory health agencies and some microbiologists suggested that HPC bacteria be considered a health-based drinking water parameter. In 1984, the U.S. Environmental Protection Agency (EPA), Office of Drinking Water, drafted the document "Drinking Water Criteria Document on Heterotrophic Bacteria"(unpublished). EPA did not move forward on promulgating an HPC-based regulation because there was insufficient clinical evidence that the addition of a maximum limit on HPC populations would provide a higher level of public health protection than that afforded by existing regulations (Reasoner, personal communication).

The U.S. Food and Drug Administration (FDA) examined the possible health effects of HPC concentrations in regards to bottled water. The FDA first examined the role of HPC human disease in 1973 and failed to issue a regulation. In 1993, the FDA reviewed the subject again in detail and wrote: "FDA still believes that, when bottled waters are free of microorganisms that are of public health significance (i.e., indicated by the absence of coliforms) and are bottled under sanitary conditions in compliance with good manufacturing practices (CGMP) regulations, the presence of heterotrophic bacteria that are part of the flora in those bottled waters normally will not pose a health risk because these organisms do not colonize the digestive tract of humans" (Federal Register, 1993).

The question remains, since the 1984 EPA draft document, whether there is more recent and compelling clinically based information to consider HPC bacteria as an indicator of increased health risk. Several epidemiological studies (Calderon, 1988, 1991; Payment et al., 1991) examined the concentration of HPC bacteria in drinking water and possible health effects. In a point-of-use study (Calderon and Mood, 1988) and a point-of-entry study (Calderon and Mood, 1991), no association between adverse health and HPC was noted. Payment et al. (1991) found that there was an association between HPC and gastroenteritis but not between the amount of drinking water and disease. Colford (2002) suggests that this anomaly may have been the result of the lack of double blinding (i.e., each consumer knew which group they were a member of - drinking water treated or not treated) of the study. A more recent Australian epidemiological study (Hellard et al., 2001) found no clinical correlation with elevated HPC populations in drinking water, but earlier studies yielded equivocal results.

\subsection{Cytotoxicity and invasiveness of HPC bacteria}

For a heterotrophic bacterium to pose a health risk when consumed in drinking water, it must be present at an infectious dose (i.e., sufficient concentrations) and be capable of infecting a human host. The capability of a microorganism to cause disease is often referred to as virulence. Frank or primary pathogens possess a wide range of virulence factors, which enable them to circumvent human defense mechanisms (Duncan and Edberg, 1995). Because epidemiological and animal infectivity studies are complex, difficult to control, expensive, and yield 
circumstantial evidence, Edberg et al. (1997) directly examined HPC bacteria with regard to cytotoxicity and invasiveness factors that directly relate to the probability of a microorganisms successfully causing disease.

HPC bacteria in tap water and bottled water were enumerated using R2A medium. R2A isolates were subsequently inoculated onto 5\% sheep blood agar, since it is physiologically equivalent to the human condition and HPC bacteria capable of causing infection (possessing virulence factors) should grow on blood agar. Those R2A isolates that did grow on blood agar were inoculated into the human colonic adenocarcinoma cell line $\left(\mathrm{CACO}-2_{\mathrm{BBe}}\left(\mathrm{C} 2_{\mathrm{BBe}}\right)\right.$ to determine their invasiveness. With respect to cytotoxicity, the $\mathrm{cfu} / \mathrm{ml}$ counts on blood agar were between $10^{-2}$ and $10^{-3}$ less on blood agar than found on R2A agar. Of the $85 \mathrm{R} 2 \mathrm{~A}$ isolates that grew on blood agar, only 10 demonstrated invasiveness. The bacteria isolated in this study did not possess significant virulence characteristics associated with a human health threat.

Other investigators (Lye and Dufour, 1991; Payment et al., 1994; Edberg, 1996; Edberg et al., 1996) reported similar results, i.e., few virulence factors such as $\alpha, \beta, \gamma$ hemolysis, adherence, and invasiveness. Smith et al. (2001) examined the ability of HPC to express virulence in highly immunosuppressed mice and found these factors lacking.

\subsection{Opportunistic pathogens}

Certain heterotrophic bacteria are considered opportunistic pathogens, i.e., capable of causing disease only in compromised human hosts. Several of these microorganisms can be found in source waters and in treated drinking water and can be enumerated on HPC media. Microorganisms most often called opportunistic pathogens in drinking water include Pseudomonas, Klebisella, and Aeromonas. It is important to understand that the basis for these genera being opportunistic pathogens is associated entirely with nosocomial (hospital-acquired) infections, not ingestion from consumption of drinking water. In hospitals, the route of transmission is not drinking water but medical devices. Duncan (1988) provides an excellent review of this difference and can be used as a model for other potential opportunistic pathogens that may be found in drinking water.
The determination that a specific microorganism is truly an opportunistic pathogen associated with drinking water and the decision by public health agencies to regulate specific microorganisms that may be found in drinking water can only be made if specific criteria indicate that a microorganism poses a health risk.

These criteria include the following:

1. There is a clinical history of an organism causing disease from ingestion of drinking water.

2. There is epidemiological evidence that drinking water, rather than food or other vectors, is a major source of disease.

3. There is sufficient evidence that the target organism, i.e., opportunistic pathogen, is found in water in sufficient concentrations and possesses virulence factors capable of causing disease in humans.

4. There is sufficient evidence that the target organism is not readily removed or inactivated by conventional water treatment processes (coagulation-filtration-disinfection).

5. There is sufficient evidence that the target organism, if surviving conventional treatment, will be viable, virulent, and present in sufficient numbers to cause disease.

6. There are robust analytical methods for the target organism, which have acceptable sensitivity, specificity, and reproducibility to accurately measure the presence of the target organism in treated drinking water.

7. The performance criteria of analytical method(s) for the target organism have been certified by the public health agency, and there is intra-laboratory performance on which to base this certification.

8. There is sufficient evidence that the target organism is present in high concentrations in these same waters.

On the basis of these criteria, Klebsiella, Pseudomonas, and Aeromonas should not be considered opportunistic pathogens in drinking water.

\subsubsection{Klebsiella}

While the genus Klebsiella is enumerated by HPC methods and is a coliform, it does not fulfill the criteria noted above and should not be considered an opportunistic pathogen from drinking wa- 
ter. In a review of waterborne Klebsiella and human disease (Duncan, 1988), the author stated the following:

Klebsiella occurs widely in nature and is often present in surface water used for human consumption or for recreational purposes. The organism can survive in water distribution systems despite chlorination. Many strains give rise to positive fecal coliform tests, even when they are the only organisms present in the water sample. The public health significance of Klebsiella in water is therefore an important concern. In the past, Klebsiella was thought to be a significant pathogen in the community causing serious primary pneumonia, but such cases are now extremely rare. Serious Klebsiella infections are today commonly seen only in hospital patients whose resistance has been impaired by their primary disease condition. There is no evidence that waterborne Klebsiella play any significant part in the epidemiology of these hospital-acquired infections. Klebsiella in water supplies should therefore not be considered a hazard to human health.

Duncan's analysis of Klebsiella applies to other potential opportunistic drinking water pathogens.

\subsubsection{Pseudomonas}

The genus Psuedomonas is also routinely enumerated in HPC determinations and considered by some to be an opportunistic pathogen when found in drinking water. In a 1997 review, "Pseudomonas aeruginosa: Assessment of Risk from Drinking Water" (Hardalo and Edberg, 1997) analyzed all reports of this bacterium as a gastrointestinal pathogen and concluded:

Pseudomonas aeruginosa is an ubiquitous environmental bacterium. It can be recovered, often in high numbers, in common food, especially vegetables. Moreover, it can be recovered in low numbers in drinking water. A small percentage of clones of $P$. aeruginosa possess the required number of virulence factors to cause infection. However, P. aeruginosa will not proliferate on normal tissue but requires previously damaged organs. Further narrowing the risk to human health is that only certain specific hosts are at risk, including patients with profound netropenia, cystic fibrosis, severe burns, and those subject to foreign device installation. Other than these very well defined groups, the general population is refractory to infection. Because of its ubiquitous nature, it is not practical to eliminate $P$. aeruginosa from our food and drinking water, but attempts to do so would produce disinfection byproducts more hazardous than the species itself. Moreover, because there is no readily available sensitive and specific means to detect and identify $P$. aeruginosa available in the field, any potential regulation governing its control would not have a defined laboratory test measure of outcome. Accordingly, attempts to regulate $P$. aeruginosa in drinking water would not yield public health protection benefits and could, in fact, be counterproductive in this regard.

\subsubsection{Aeromonas}

Aeromonas is another genus naturally found in drinking water. It may or may not be isolated on HPC media (Payment et al., 1994) methods and has been suggested as an opportunistic pathogen when present in drinking water. Similar to the above analysis as to why neither Klebsiella nor Pseudomonas is an opportunistic pathogen when present in drinking water, Aeromonas also fails to meet most, if not all, of the above criteria as a gastrointestinal pathogen by ingestion.

In a review paper by Edberg and Allen (in preparation) entitled "Issues for Microbial Regulations: Aeromonas as a Model," the authors provide data to make the following observations:

1. A small percentage of Aeromonas hydrophila isolates can cause gastroenteritis and enteritis and produce modest, self-limited infection. Although most cases are food-borne, the few waterborne cases were associated with ingestion of untreated drinking water from shallow wells. These waters are also very high in assimilable organic carbon concentrations.

2. The concentration of $A$. hydrophila from food is much higher, by several logs, when compared to water sources. The species A. hydrophila is the most important. Only a small percentage of $A$. 
hydrophila isolates possess human virulence factors.

3. There is little overall similarity between diarrheal and water isolates. Water isolates that can infect humans are rare.

4. There are many species of Aeromonas. Based on isolates from cases of gastroenteritis, A. hydrophila is the only one associated with human disease. Even within the species Hydrophila, only a small percentage of isolates produce sufficient virulence factors to cause disease. Accordingly, laboratory tests for Aeromonas must not only be specific for the species but also the virulence factors.

5. Aeromonas, including A. hydrophila, are of low virulence. Animal studies show it requires large numbers of bacteria inoculated intraperitoneally to cause disease. Human feeding studies with ingestion of $10^{8}$ cells have not produced disease.

6. No Aeromonas medium that has acceptable sensitivity, specificity, and reproducibility for the detection of A. hydrophila has been developed or used extensively for drinking water. There has not been widespread use or testing of media for this bacteria from drinking water.

7. Aeromonas isolates exhibit no exceptional resistance to chlorine disinfection at concentrations and exposure times typically found in public water systems.

Based on these observations, there is insufficient evidence that $A$. hydrophila can be considered an opportunistic pathogen when present in drinking water, and it would be inappropriate to consider monitoring or regulating this organism at this time.

\section{Significance of HPC populations in drinking water}

As mentioned previously, the number of HPC bacteria in drinking water varies widely. It depends on the quality of the source water, the types and efficacy of treatment, the type and concentration of disinfection residuals, the age and the condition of the storage and distribution system, the concentration of dissolved organics in the treated drinking water, the ambient temperature of the raw and finished water, the elapsed time between the water treatment plant and sampling locations, and, of course, the HPC method and time and temperature of incubation. These are just some examples of variables that have a profound effect on the enumeration of HPC bacteria. With all these of variables, it is obvious that the range of HPC populations in drinking water is considerable, i.e., $<0.02$ to $10^{4} \mathrm{cfu} / \mathrm{ml}$ or higher.

While there is a lack of health-based justification for setting an upper HPC limit in drinking water, a number of countries have established mandatory limits for HPC bacteria in drinking water. As would be expected, different countries use a variety of terms to describe their respective bacterial count method, specify different analytical procedures (media, temperature, time) that can be used, and establish different maximum acceptable counts, which can range from 20 to $1000 \mathrm{cfu} / \mathrm{ml}$. Some have argued that lower HPC bacterial populations in drinking water are more desirable than higher populations, but there is no epidemiological evidence that higher HPC populations have any public health significance. Typically, public water systems with conventional treatment are able to limit HPC bacterial populations to below 100 $\mathrm{cfu} / \mathrm{ml}$ in the distribution system, although many systems experience increased HPC populations $(500-1000 \mathrm{cfu} / \mathrm{ml})$ during the summer months. Bottled water that has no disinfectant residual may have much higher HPC populations. While a maximum HPC population of $500 \mathrm{cfu} / \mathrm{ml}$ in drinking water is often cited as a health-based standard, this perception is fallacious and not based on fact. As reviewed below, there is no health-based substantiation for HPC regulations.

\subsection{Origin of basis for establishing maximum HPC populations}

The commonly used "level of concern", $500 \mathrm{cfu} /$ $\mathrm{ml}$, originated from studies that examined the effect of HPC populations on analytical recovery of total coliforms. It was never a health-based action level.

Possibly the first evidence that high HPC populations may interfere with the detection of coliforms by the multiple-tube-fermentation method (MTF) or the membrane-filtration method (MF) was suggested by McCabe et al. (1970). In reviewing the bacteriological results from a 1969 survey of 969 public water systems in the US, the authors stated: "While bacteria 
enumerated by plate count do not usually have a direct health significance, heavy growths of bacteria and other microorganisms do indicate the potential for contamination. Also, research findings (Geldreich, 1972) suggest that high plate counts inhibit the growth of coliform bacteria on laboratory media, thereby obscuring their presence". They further examined the question of interference specifically and reported that the 1969 survey data found the frequency of detecting total and fecal coliforms by the membranefiltration method increased as the SPC levels increased to $500 \mathrm{cfu} / \mathrm{ml}$, but decreased in frequency when SPC levels exceeded $1000 \mathrm{cfu} / \mathrm{ml}$.

To further examine this interference phenomenon, Geldreich et al. (1978) collected 613 samples from 32 dead-end water main flushing sites in the Cincinnati, $\mathrm{OH}$, distribution system. This study found 76 samples contained coliforms by the MTF procedure, but only 19 by the MF procedure. Data analysis demonstrated a correlation between excess SPC densities and desensitization of the MF method when SPC bacteria exceeded $500 \mathrm{cfu} / \mathrm{ml}$. Other researchers (Clark, 1980; Herson and Victoreen, 1980; Means and Olson, 1981; Seidler et al., 1981; Burlingame et al., 1984; Franzblau et al., 1984) have also reported method desensitization or coliform antagonism by HPC bacteria clustering in the $500-1000 \mathrm{cfu} / \mathrm{ml}$ range. These investigations demonstrated that high SPC (HPC) densities can substantially interfere with both the MTF method and especially the MF method, but that this phenomenon may not occur consistently.

One of the co-authors of the 1978 report is also a co-author here. From the original analytical data demonstrating interferences by HPC on the recovery of coliforms, to 25 years later, the following have been demonstrated:

1. There is no EPA, FDA, or WHO health-based HPC regulation.

2. HPC concentrations are mentioned only twice in EPA regulations: first, as a cause of false-negative coliform tests in which lactose-based media (i.e., MTF and MF) are employed and second, as a surrogate for chlorine residuals in distribution systems.

3. Suppression of coliform recovery only occurs with lactose-based media formulations. Defined Substrate Technology methods (e.g., Colilert ${ }^{\circledR}$, Colisure ${ }^{\circledR}$ ) do not suffer from HPC suppression.

\subsection{Significance and impact of HPC bacteria on coliform detection methodology}

The ramifications of HPC populations greater than $500 \mathrm{cfu} / \mathrm{ml}$ in drinking water are significant because they desensitize membrane-based coliform methods that contain lactose. Given that routine analysis of drinking water for coliforms and Escherichia coli is the most common and the most important determination as to the microbiological safety of drinking water, desensitization by HPC bacteria may have grave public health consequences. For this reason, it is imperative that HPC analysis be performed in parallel with each MF coliform/E.coli determination. This quality assurance approach ensures that coliform/E. coli data, especially negative results, accurately reflect the true microbiological quality of drinking water.

In the late 1980s, the development of the Defined Substrate Technology (Edberg et al., 1988) for the simultaneous enumeration of coliforms and E.coli provided a method that was not subject to HPC interferences, resulting in greater confidence that negative coliform/E.coli drinking water samples correctly reflect their microbiological quality.

\section{Uses of heterotrophic plate count measurements}

While there is no validated clinical evidence that the consumption of drinking water containing high levels of HPC bacteria poses increased health risks, HPC measurements do have value as a tool to ensure drinking water quality. The purpose of water treatment is to provide a safe water supply through the use of unit processes that reduce turbidity, and chemical, and microbiological contaminants to desired levels. Beyond the water quality gains as a result of treatment, there remains the challenge of maintaining water quality during storage and distribution prior to reaching consumers.

According to Reasoner (1990), HPC is a useful tool for

1. monitoring the efficiency of the water treatment process, including disinfection;

2. obtaining supplemental information on HPC levels that may interfere with coliform detection 
in water samples collected for regulatory compliance monitoring;

3. assessing changes in finished-water quality during distribution and storage and distribution system cleanliness;

4. assessing microbial growth on materials used in the construction of potable water treatment and distribution systems;

5. measuring bacterial regrowth or after growth potential in treated drinking water;

6. monitoring bacterial population changes following treatment modifications such as a change in the type of disinfectant used.

\section{Summary}

1. While the literature documents the universal occurrence of HPC bacteria or autochthonous flora in soil, food, air, and all types of water, there is insufficient clinical and epidemiological evidence to conclude that HPC bacteria in drinking water pose a health risk. For this reason, it is not possible to establish health-based standards for HPC bacteria in drinking water.

2. The various methods used to enumerate HPC bacteria differ significantly in the number and genera detected, and HPC data from different methods are not necessarily comparable.

3. HPC populations greater that $500-1000 \mathrm{cfu} / \mathrm{ml}$ in drinking water can interfere with coliform $/ E$. coli analysis by lactose-based methods, which include the membrane-filtration method.

4. Klebsiella, Pseudomonas, and Aeromonas cannot be considered opportunistic pathogens when found in drinking water, since there is no clinical or epidemiological evidence to support this designation.

5. HPC determinations can be a useful tool to the monitor efficacy of drinking water treatment processes and undesirable changes in bacterial water quality during storage and distribution, but not because of health-risk reasons.

\section{References}

Briganti, L.A., Wacker, S.C., 1995. Fatty acid profiling and the identification of environmental bacteria for drinking water util- ities. Awwa Research Foundation and American Water Works Association, Denver, p. 89.

Burlingame, G.A., McElhaney, J., Bennett, B., Pipes, W.O., 1984. Bacterial interference with coliform sheen production on membrane filters. Journal of Applied and Environmental Microbiology 47 (1), 56-60.

Calderon, R.L., Mood, E.W., 1988. Bacterial colonizing pointof-use, granular activated carbon filters and their relationship to human health. U.S. Environmental Protection Agency. CR-811904-01-0.

Calderon, R.L., Mood, E.W., 1991. Bacterial colonizing pointof-entry, granular activated carbon filters and their relationship to human health. U.S. Environmental Protection Agency. CR-813978-01-0.

Clark, J., 1980. The influence of increasing numbers of nonindicator organisms upon the detection of indicator organisms by the membrane filter and presence-absence tests. Canadian Journal of Microbiology 26, 827-832.

Colford, J.M., 2002. Participant binding and gastrointestinal illness in a randomized, controlled trial of in-home drinking water intervention. Emerging Infectious Diseases 8, 29-36.

Duncan, I.B.R., 1988. Waterborne Klebsiella and human disease. Toxicity Assessment 3 (5), 581-598.

Duncan, H.E., Edberg, S.C., 1995. Host-microbe interaction in the gastrointestinal tract. Critical Reviews in Microbiology 21 (2), $85-100$.

Edberg, S.C., 1996. Assessing health risk in drinking water from naturally occurring microbes. Journal of Environmental Health 58 (6), $18-24$.

Edberg, S.C., 1997. Are there human indicators of emerging public health threat? Under the Microscope-Examining Microbes in Ground Water. Awwa Research Foundation Conference, Boston. Lincoln, Nebraska, USA. ISBN 0189-8670895-1.

Edberg, S.C., Allen, M.J., in preparation. Issues for microbial regulation: Aeromonas as a model.

Edberg, S.C., Allen, M.J., Smith, B.D., 1988. National field evaluation of a defined substrate method for the simultaneous enumeration of total coliforms and Escherichia coli from drinking water. Journal of Applied and Environmental Microbiology 54 (6), 1003-1008.

Edberg, S.C., Gallo, P., Kontnick, C., 1996. Analysis of the virulence characteristics of bacteria isolated from bottled, water cooler, and tap water. Microbial Ecology in Health and Disease 9, 67-77.

Edberg, S.C., Kopps, S., Kontnick, C., Escarzaga, M., 1997. Analysis of cytotoxicity and invasiveness of heterotrophic plate count bacteria (hpc) isolated from drinking water on blood media. Journal of Applied and Environmental Microbiology 82 (4), $455-461$.

Federal Register, 1993. Quality standards for foods with no identification standards: bottled water 58 (192), 52042-52049.

Franzblau, S., Hinnebusch, B., Kelley, L., Sinclair, N., 1984. Effect of noncoliforms on coliform detection in potable groundwater. Journal of Applied and Environmental Microbiology 48, $142-148$.

Geldreich, E., 1972. Is the total count necessary? Proceedings of American Water Works Association Water Quality Technology Conference, Cincinnati. 
Geldreich, E., Allen, M.J., Taylor, R.H., 1978. Interferences to coliform detection in potable water supplies. U.S. Environmental Protection Agency. EPA-EPA570/9-78-00C.

Hardalo, C., Edberg, S.C., 1997. Pseudomonas aeruginosa: assessment of risk from drinking water. Critical Reviews in Microbiology 23 (1), 47-75.

Hellard, M.E., Stewart, M.I., Forbes, A.B., Fairley, C.K., 2001. A randomized, blinded, controlled trial investigation of the gastrointestinal health effects of drinking water quality. Environmental Health Perspectives 109 (8), 773-778.

Herson, D., Victoreen, H., 1980. Hindrance of coliform recovery by turbidity and non-coliforms. U.S. Environmental Protection Agency- EPA600/2-80-097.

Jackson, R.W., Osborne, K., Barnes, G., Joliffe, C., Zamani, D., Roll, B., Stillings, A., Herzog, D., Cannon, S., Loveland, S., 2000. Multiregional Evaluation of the SimPlate ${ }^{\circledR}$ heterotrophic plate count method compared to the standard plate count agar pour plate method in water. Journal of Applied and Environmental Microbiology 66 (1), 453-454.

LeChavallier, M., Seidler, R., Evans, T., 1980. Enumeration and characterization of standard plate count bacteria in chlorinated and raw water supplies. Journal of Applied and Environmental Microbiology 40, 922-930.

Lye, D.J., Dufour, A.P., 1991. A membrane filter procedure for assaying cytotoxic activity in heterotrophic bacteria isolated from drinking water. Journal of Applied Bacteriology 70, 89-94.

McCabe, L.J., Symons, J.M., Lee, R.D., Robeck, G.G., 1970. Sur- vey of community water supply systems. Journal of American Water Works Association 62, 670-687.

Means, E., Olson, B., 1981. Coliform inhibition by bacteriocin-like substances in drinking water distribution systems. Applied and Environmental Microbiology 42, 506-512.

Payment, P., Franco, E., Richardson, L., Siemiatychi, J., 1991. Gastrointestinal health effects associated with the consumption of drinking water produced by point-of-use domestic reverseosmosis filtration units. Journal of Applied and Environmental Microbiology 57, 945-948.

Payment, P., Coffin, E., Paquette, G., 1994. Blood agar to detect virulence factors in tap water heteroptrohic bacteria. Journal of Applied and Environmental Microbiology 60, 1179-1183.

Reasoner, D.R., 1990. Monitoring heterotrophic bacteria in potable water. In: McFeters, G.A. (Ed.), Drinking Water Microbiology-Progress and Recent Developments. Springer-Verlag, New York, pp. 452-477.

Seidler, R., Evans, T., Kaufman, J., Warvick, C., LeChevallier, M., 1981. Limitations of standard coliform enumeration techniques. U.S. Environmental Protection Agency-EPA 570/9-83-001.

Smith, B.G., Lye, D.J., Messer, J.W., 2001. Occurrence of heterotrophic bacteria with virulence characteristics in potable water, Poster Q-412. 100th Annual Conference American Society for Microbiology, Orlando, FL.

Wadhwa, S.G., Khaled, G.H., Edberg, S.C., 2002. Comparative microbial character of consumed food and drinking water. Critical Review in Microbiology 28, 249-279. 